\title{
Pemphigus foliaceus patients (Fogo Selvagem) treated with kinesiotherapy presented lower levels of proinflammatory cytokines
}

\author{
Rodolfo Pessato Timóteo ${ }^{1, *}$, Helioswilton Sales-Campos², Marcos Vinicius Silva', Djalma Alexandre Alves da Silva', \\ Jonatas Da Silva Catarino', Marlos Aureliano Dias de Sousa', Virmondes Rodrigues Júnior', Leonardo Eurípedes de Andrade e Silva', \\ Ana Carolina Silva Bittencourt', Élida Mara Carneiro ${ }^{3}$, Carlo José Freire Oliveira' \\ ${ }^{1}$ Federal University of Triângulo Mineiro, Uberaba, Brazil \\ Federal University of Goiás, Goiânia, Brazil \\ ${ }^{3}$ Physiotherapy Division (EBSERH/UFTM). Clinical Hospital of Federal University of Triângulo Mineiro, Uberaba, Brazil
}

Fogo Selvagem (FS) is a rare autoimmune disease characterized by acantholysis and inflammation of the epidermis. It was evidenced in this disease the increase of pro-inflammatory cytokines levels which can be influenced by physical activities. Kinesiotherapy, as physiotherapeutic interventions, was associated improvement levels of the quality of live, mainly the pain. Understanding the impact of such methodology in immunology of the FS, may constitute an alternative and effective approach. We compare the levels of serum cytokines and chemokines between nine patients with FS submitted to kinesiotherapy for 12 weeks and ten patients not submitted to kinesiotherapy. The kinesiotherapy was composed by self-stretching followed by a resistance training for upper and lower limbs. The protocol was carried out in three sections of eight to ten repetitions with $70 \%$ of the maximum load measured by test maximum of ten repetitions. After strengthening period patients performed a passive stretching. The training sessions lasted 50 min and were performed 3 times a week at least 12 weeks. Cytokines and chemokines were assessed in plasma using enzyme-linked immunosorbent assay and/or cytometric bead array. Patients with FS were being kinesiotherapy presented minors levels of interferon- $\gamma$, interleukin (IL)-17, IL-22, and IL-15 when compared to those not submitted to kinesiotherapy. No differences were observed for the detection of the chemokines chemokine ligand (CCL)-2, CCL-3, CCL-5, CCL-11, C-X-C motif chemokine 8 (CXCL-8), and CXCL-10. These results suggest that kinesiotherapy had a positive impact on inflammatory markers that are associated with disease worsening in FS.

Keywords: Kinesiotherapy, Pemphigus foliaceus, Cytokines, Chemokines

\section{INTRODUCTION}

Pemphigus foliaceus $(\mathrm{PF})$ is a disorder from a group of immunemediated diseases characterized by the production of IgG4 antibodies targeting desmoglein-1, which causes loss of cell adhesion in the epidermis, thus leading to the formation of discrete fluidcontaining blisters in the skin (Grando, 2012). This process triggers a painful, disabling inflammatory process and reduces the quality of life of patients (Timóteo et al., 2010). The endemic form of PF is known as "Fogo Selvagem" (FS) and presents partic- ularities in the Southeast and Midwest regions in Brazil, reaching up to $3 \%$ of the entire population (Aoki et al., 2015; Culton et al., 2008).

The immune system of patients with FS is locally and systematically disturbed. FS activity seems to be correlated with higher levels of interleukin (IL)-6, tumor necrosis factor (TNF)- $\alpha$, IL-17, IL-1 and interferon (IFN)- $\gamma$ in skin (Arakawa et al., 2009; LópezRobles et al., 2001; Rodrigues et al., 2009; Timóteo et al., 2017; Tojo et al., 2013), and IL-22 and IL-8 in serum. Furthermore, an imbalance in the lymphocytes $\mathrm{T}$ helper (Th)1/Th2 ratio with a

\footnotetext{
${ }^{*}$ Corresponding author: Rodolfo Pessato Timóteo

(iD) https://orcid.org/0000-0002-4273-8201

Federal University of Triângulo Mineiro, Av. Getúlio Guaritá S/N, Laboratory of Immunology, Uberaba, Minas Gerais, 38015-050, Brazil

E-mail: rodolfo_pessa@hotmail.com

Received: March 19, 2019 / Accepted: April 24, 2019
}

This is an Open Access article distributed under the terms of the Creative Commons Attribution Non-Commercial License (http://creativecommons.org/licenses/by-nc/4.0/) which permits unrestricted non-commercial use, distribution, and reproduction in any medium, provided the original work is properly cited. 
trend towards a Th2 response have already been identified in cells isolated from patients with FS under corticosteroid therapy (Rocha-Rodrigues et al., 2003).

Because of the central role of immune system in the disease onset and outcome, immunosuppressive drugs, like corticosteroids and immunobiologicals, have been used to treat FS (Kasperkiewicz et al., 2017). Though these therapeutic approaches have been experienced, more studies are required to clarify their safeness and effectiveness. Alongside pharmacological therapy, kinesiotherapy is a complementary intervention initially used to improve the quality of life of patients in distinct diseases. The influence of physical exercise on immune responses is not fully understood, however, changes in circulating cytokines are noticeable soon after, few hours later or even days after physical training (Leicht et al., 2013). The influence of physical exercise in immune response was verified after strenuous exercise in humans (Perandini et al., 2012), and after moderate physical activity in animal models of systemic lupus erythematosus (Aqel et al., 2017). Additionally, a reduction of pain, improvement of physical aspects and in quality of life was observed in patients with PF under immunosuppressive therapy and physical exercise protocol (kinesiotherapy) (Timóteo et al., 2010).

Despite these evidences regarding the beneficial role of physical activity/kinesiotherapy in the modulation of immune system in different scenarios, there are no studies that can clarify if this improvement is related to significant changes in immunological parameters, especially cytokines and chemokines. Therefore, this study aimed to verify the putative differences in circulating cytokines and chemokines in patients with FS submitted or not to kinesiotherapy.

\section{MATERIALS AND METHODS}

\section{Study design}

This was an exploratory and quantitative study that evaluated the levels of cytokines and chemokines in patients with FS submitted or not to kinesiotherapy. All patients undergoing kinesiotherapy were under this treatment for at least 12 weeks. This physical intervention was part of the hospital routine for patients who accepted, based on patients' choice, to participate in the proposed therapy. Therefore, kinesiotherapy was not proposed in the context of adjuvant treatment of patients with FS, since it is only an option if the patient has an interest in participating in some activity during hospitalization. The others patients with FS were not submitted to kinesiotherapy by option or because they were unable to go to the hospital to perform it. All FS patients submitted or not to kinesiotherapy were under drug treatment. A control group with healthy subjects was also used. All participants agreed to participate in the study by signing the free and informed consent form. This study was conducted in accordance with the Declaration of Helsinki and the protocol approved by the Ethics Committee of the Federal University of Triângulo Mineiro with protocol number 1.341.124.

\section{Participants}

For this study 10 healthy subjects, 10 patients with FS under immunosuppressive treatment, and nine patients with FS under immunosuppressive therapy and submitted to kinesiotherapy protocol, were included. Were included in the submitted kinesiotherapy group patients undergoing kinesiotherapy for at least 12 weeks. For the group not submitted to kinesiotherapy, were randomly included patients were only on medication treatment and did not perform any type of regular physical activity.

\section{Chemokine and cytokine production}

The production of IL-1 $\beta$, IL-5, IL-12, IL-13, IL-15, IL-22, IL23, IL-33, chemokine (C-C motif) ligand 2 (CCL2) also referred to as monocyte chemoattractant protein 1 (MCP1), C-X-C motif chemokine 10 (CXCL-10) also referred to as Interferon Gamma-Induced Protein 10 (IP-10), and CCL-11 (Eotaxin-1) was assessed in plasma using the enzyme-linked immunosorbent assay (R\&D Systems, San Diego, CA, USA), following the manufacturer's instructions. Cytometric Bead Array (BD Bioscience, San Jose, CA, USA) was used for detection of TNF- $\alpha$, IFN- $\gamma$, transforming growth factor beta, IL-2, IL-4, IL-6, IL-9, IL-10, IL-17A, CCL-5 (RANTES), C-X-C motif chemokine 8 (CXCL8) (IL-8) and CCL3 (MIP-1 $\alpha$ ).

\section{Kinesiotherapy protocol}

The 12-week kinesiotherapy protocol was performed three times a week for approximately sixty minutes under the supervision and guidance of a physiotherapist. Kinesiotherapy was composed of resistive exercises and active stretches for all parts of the body. For the resisted exercises, loads with up to $70 \%$ of the maximum load evaluated by the test of 10 maximum repetitions (Alexanderson et al., 2007) were used and performed in three sets of 10 repetitions, according to the protocol of American College of Sports (American College of Sports Medicine, 2009). The active stretches were performed at the beginning and at the end of each session with a total of three sets of stretching for a period of ap- 
proximately twenty seconds/each. The same physiotherapist supervised all kinesiotherapy sessions. Blood samples were collected in the morning (between 8:00 a.m. and 11:00 p.m.) $48 \mathrm{hr}$ after the last session of exercises and 12 weeks after the beginning of the protocol.

\section{Data analysis and statistics}

For all variables normal distribution and homogeneous variance were tested. The D'Agostino-Pearson test was used to assess normality for all variables. In cases of non Gaussian distribution of data, the nonparametric Mann-Whitney test was applied. Multiple comparisons relating to the medians of values for more than two groups were made using the Kruskal-Wallis nonparametric test followed by Dunn test. The observed differences were considered significant when $P<0.05$ (5\%). For correlations the Spearman test was used. Statistical analysis was performed using the software Graphpad Prism (GraphPad Software 6.0, La Jolla, CA, USA).

\section{RESULTS}

\section{Participants}

Groups were considered homogeneous relative to age, gender, skin color and residence type (Table 1). All patients with FS presented lesions that reached cutaneous involvement between 18\% and $45 \%$ of the body surface (Rule of nine of Wallace) with lesions in phase of re-epithelialization and/or granulation and hy-

Table 1. Age, gender, skin color, and housing area of pemphigus foliaceus patients and control groups

\begin{tabular}{|c|c|c|c|c|}
\hline Variable & Control & $\begin{array}{c}\text { PF under } \\
\text { pharmacological } \\
\text { therapy }\end{array}$ & $\begin{array}{c}\text { PF with } \\
\text { pharmacological } \\
\text { therapy and } \\
\text { kinesiotherapy }\end{array}$ & $P$-value \\
\hline Age (yr), mean $\pm S D$ & $30 \pm 9.54$ & $27 \pm 12.55$ & $42 \pm 15.70$ & 0.086 \\
\hline Gender (n) & & & & $>0.999$ \\
\hline Female & 7 & 5 & 6 & \\
\hline Male & 3 & 5 & 3 & \\
\hline Skin colors (n) & & & & $>0.999$ \\
\hline Mulattoes & 5 & 1 & 4 & \\
\hline White & 2 & 5 & 4 & \\
\hline Black & 3 & 4 & 1 & \\
\hline Housing área (n) & & & & $>0.999$ \\
\hline Urban & 5 & 5 & 3 & \\
\hline Urban whith rural area & 4 & 3 & 4 & \\
\hline Rural area & 1 & 2 & 2 & \\
\hline
\end{tabular}

PF, pemphigus foliaceus; SD, standard deviation. perpigmentation. All patients were treated with prednisone with dosages ranging from $10 \mathrm{mg}$ to $60 \mathrm{mg}$ /day (Supplementary Table 1). No correlation was found between the cutaneous involvement and the glucocorticoid dosage in both patients groups. As well no correlations was found between medical treatment period and glucocorticoid dosage. Was verified only a correlation between cutaneous involvement and medical treatment period in PF under pharmacological therapy group $(P=0.009, r=0.835$; Spearmen test).

\section{Kinesiotherapy modulates key cytokines in serum of patients with the endemic form of PF}

Patients with FS who underwent kinesiotherapy had reduced levels of IFN- $\gamma$, IL-17, and IL-22 when compared to the group of patients receiving immunosuppressive therapy alone (Fig. 1A, B, $\mathrm{G}$, and $\mathrm{H}$, respectively). No differences were observed for the production of IL-6 (Fig. 1C), IL-5 (Fig. 1D), IL-13 (Fig. 1E), and IL10 (Fig. 1F). These results indicate that kinesiotherapy may induce a reduction in key cytokines in the development of FS. The kinesiotherapy protocol appeared to have no influence on the production of IL-4 (data not show).

Kinesiotherapy induced a reduction in the production of IL-15 when compared to patients with FS not submitted to kinesiotherapy, reinforcing the anti-inflammatory role of physical intervention in this scenario (Fig. 2D, F). No differences were observed for IL-2 (Fig. 2A), TNF- $\alpha$ (Fig. 2B), IL-12 (Fig. 2C), and IL-33 (Fig. $2 \mathrm{E})$. Cytokines IL- $4, \mathrm{IL}-23$, and IL-1 $\beta$ were not detected in plasma of healthy subjects or PF patients submitted or not to kinesiotherapy (data not shown).

\section{Kinesiotherapy seems not to be effective in the modulation of chemokines in FS}

No differences were detected for the levels of CXCL8 (Fig. 3A), CCL2 (Fig. 3B), CCL5 (Fig. 3C), CCL11 (Fig. 3D), and CCL10 (Fig. 3E). MIP- $\alpha$ was not detected (data not shown).

\section{DISCUSSION}

In recent years, a great number of researchers have sought to investigate new alternatives of treatment or complementary therapies for FS. One of the main goals of such approaches relies on improving the effectiveness in the modulation of immune system thus, favoring a reduction in inflammation, prolonging the periods of remission and a promising outcome. Despite this observation, the role of kinesiotherapy has never been addressed in this 

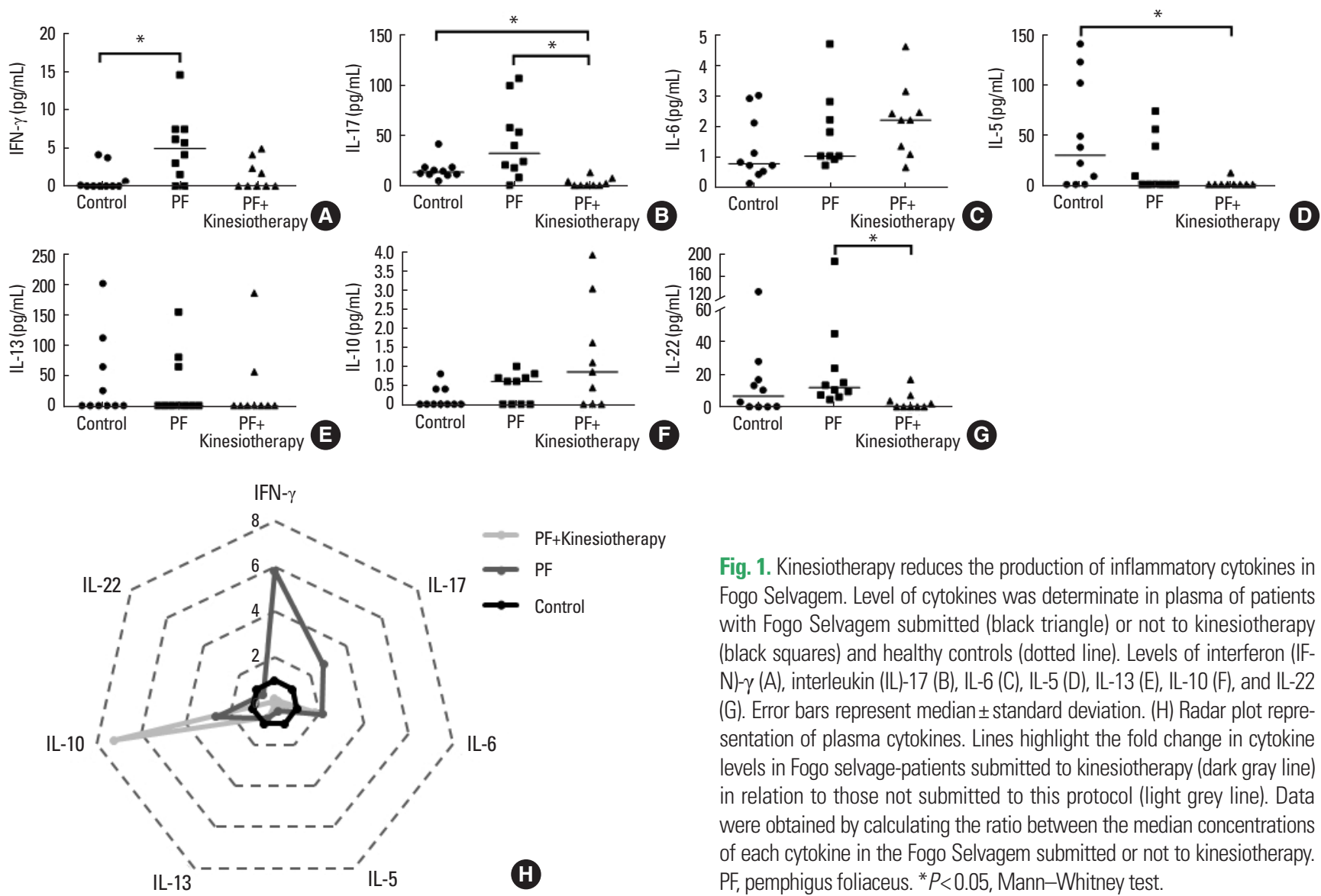

Fig. 1. Kinesiotherapy reduces the production of inflammatory cytokines in Fogo Selvagem. Level of cytokines was determinate in plasma of patients with Fogo Selvagem submitted (black triangle) or not to kinesiotherapy (black squares) and healthy controls (dotted line). Levels of interferon (IFN)- $\gamma(A)$, interleukin (IL)-17 (B), IL-6 (C), IL-5 (D), IL-13 (E), IL-10 (F), and IL-22 (G). Error bars represent median \pm standard deviation. $(\mathrm{H})$ Radar plot representation of plasma cytokines. Lines highlight the fold change in cytokine levels in Fogo selvage-patients submitted to kinesiotherapy (dark gray line) in relation to those not submitted to this protocol (light grey line). Data were obtained by calculating the ratio between the median concentrations of each cytokine in the Fogo Selvagem submitted or not to kinesiotherapy. PF, pemphigus foliaceus. ${ }^{*} P<0.05$, Mann-Whitney test.

scenario. Thus, our results pointed to a beneficial role of kinesiotherapy as adjuvant treatment besides of its ability to reduce the levels of IFN- $\gamma$, IL-22, IL-17, and IL-15 in FS. However, kinesiotherapy seems not to affect the levels of chemokines in plasma of patients with FS.

Despite of the limited patients' number in our study, both groups were considered homogeneous relative to age, gender, skin color, and residence type. This homogeneity between patient groups was probably of the Brazilian epidemiological and environmental factors cited in previous study of our group and others studies (Hans-Filho et al., 2018; Timóteo et al., 2010). Clinicals characteristics as medical treatment time, concomitant medication dosage and cutaneous involvement did not present correlations between the patients groups studied. These characteristics may be due to the limited number of patients between the groups, individualization in the pharmacological treatment and/ or different responses to different dosages of corticosteroids.

Different studies have addressed the impact of kinesiotherapy as a complementary therapy on the treatment of immune-mediated diseases. Such approach has been used in systemic lupus erythe- matosus (Rodríguez Huerta et al., 2016; Walsh et al., 2011), psoriasis, psoriatic arthritis (Kimball et al., 2008), and rheumatoid arthritis (Brenol et al., 2013). In these cases, the intervention with physical exercise was associated with improvement of clinical signs of disease. Despite the amelioration observed the immune-mechanisms involved in clinical improvement were poorly explored.

The participation of specific cytokines in the pathogenesis of FS is a matter of debate and some of them present conflicting role depending on the location they are analyzed. Higher levels of IFN- $\gamma$ can be associated either with disease worsening or amelioration. Locally in skin, higher levels of IFN- $\gamma$ in the inflammatory exudate of lesions in FS, together with TNF- $\alpha$ and IL-1, were implicated in mechanisms of tissue injury (Rodrigues et al., 2009). On the other hand, a recent publication from our group, suggested that higher plasma levels of IFN- $\gamma$ might have a putative protective role in FS progression (Timóteo et al., 2017). In this present study, the reduction in IFN- $\gamma$ in plasma was observed in patients with FS submitted to kinesiotherapy protocol. One hypothesis to explain this controversial result, may rely on the adjuvant 

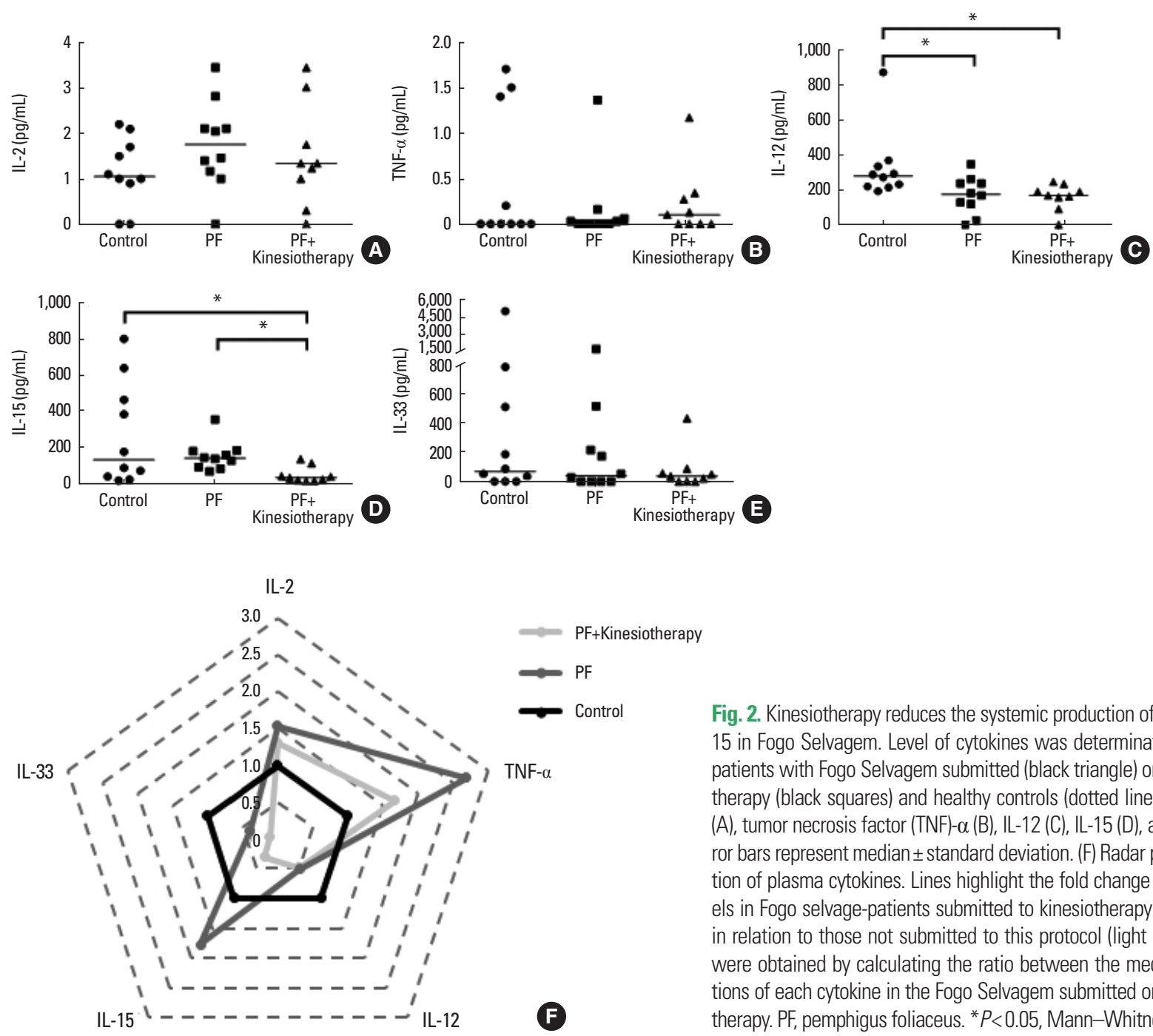

Fig. 2. Kinesiotherapy reduces the systemic production of interleukin (IL)15 in Fogo Selvagem. Level of cytokines was determinate in plasma of patients with Fogo Selvagem submitted (black triangle) or not to kinesiotherapy (black squares) and healthy controls (dotted line). Levels of IL-2 (A), tumor necrosis factor (TNF)- $\alpha$ (B), IL-12 (C), IL-15 (D), and IL-33 (E). Error bars represent median \pm standard deviation. (F) Radar plot representation of plasma cytokines. Lines highlight the fold change in cytokine levels in Fogo selvage-patients submitted to kinesiotherapy (dark gray line) in relation to those not submitted to this protocol (light grey line). Data were obtained by calculating the ratio between the median concentrations of each cytokine in the Fogo Selvagem submitted or not to kinesiotherapy. PF, pemphigus foliaceus. ${ }^{*} P<0.05$, Mann-Whitney test.

anti-inflammatory role of kinesiotherapy that have induced a reduction in key inflammatory cytokines such as IL-17 and IL-22, which are clearly associated to disease worsening. Thus, the modulation of these cytokines may have down regulated the systemic production of IFN- $\gamma$.

IL-22 is associated to the regulation of tissue cells in skin, small intestine, liver, colon, and respiratory system (Wolk et al., 2004). Th17 and Th22 cells mostly produce this cytokine (Trifari et al., 2009). Despite its physiological role, IL-22 may also be involved in inflammatory process. Different studies have demonstrated a positive correlation between higher levels of IL-22 and inflammatory disorders in skin, such as psoriasis (Benham et al., 2013) and atopic dermatitis (Nograles et al., 2009). In a recent publication, our group demonstrated that FS is characterized by systemic production of IL-22 (Timóteo et al., 2017). Though the role of IL-22 in FS is still poorly addressed, we cannot underestimate its importance in disease pathogenesis. In this present study, patients with FS submitted to kinesiotherapy, had lowered the levels of IL-22, which suggests the importance of such adjuvant therapy in the amelioration of disease. However, the mechanisms behind this observation still demand further clarification.

IL-17 is a cytokine detected in different inflammatory diseases and is closely involved in chronic inflammation observed during the pathogenesis of some immune-mediated diseases. Th17 cells are the main source of IL-17, and several molecules associated to this lymphocyte are strongly implicated in the pathogenesis of psoriatic skin lesions (Johansen et al., 2009). Because of the role of IL-17 in this scenario, it has been used as a potential treatment target in psoriasis (Greig, 2016; Markham, 2016). Though the role of IL-17 in FS has not yet been demonstrated, it is known 

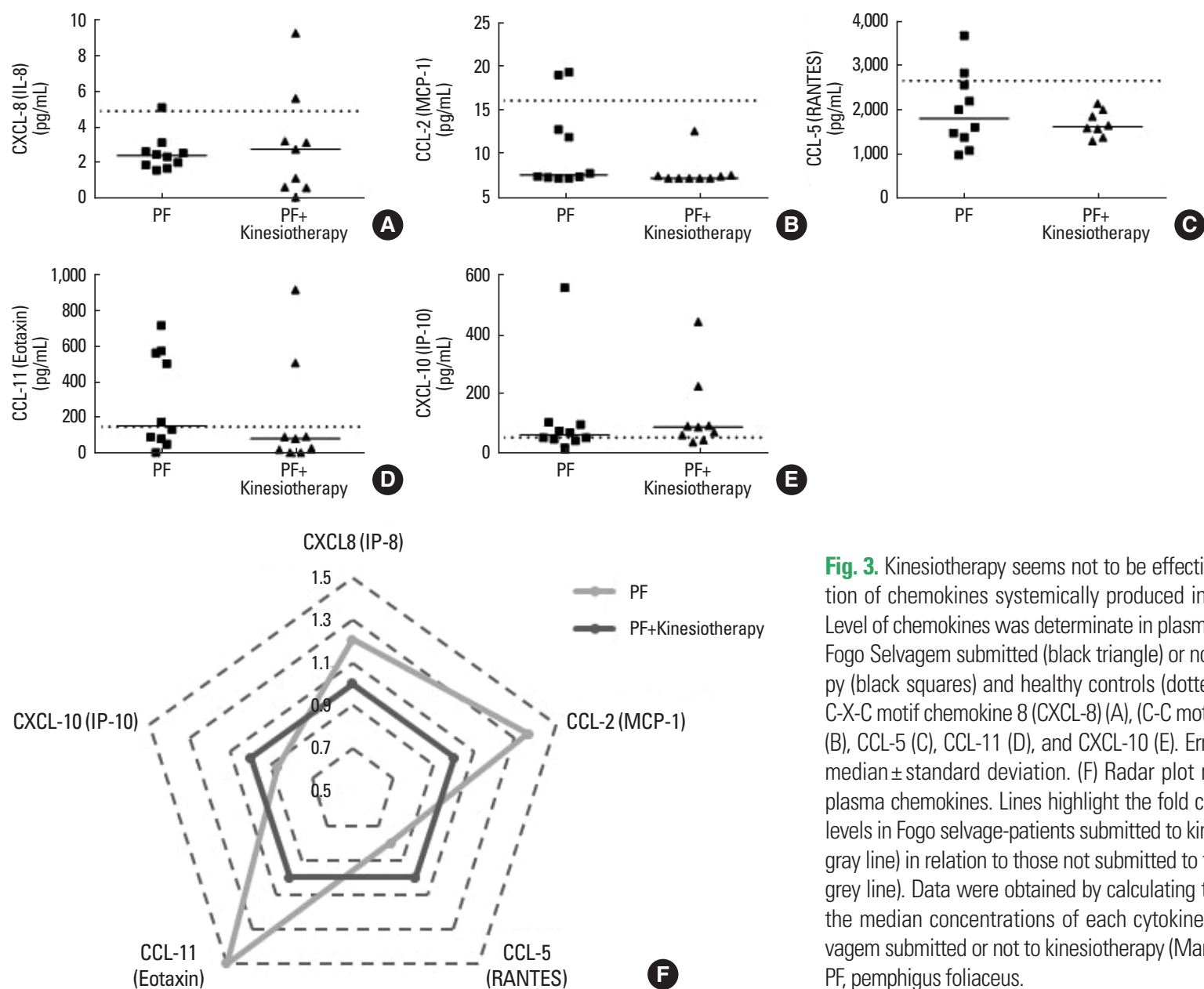

Fig. 3. Kinesiotherapy seems not to be effective in the modulation of chemokines systemically produced in Fogo Selvagem. Level of chemokines was determinate in plasma of patients with Fogo Selvagem submitted (black triangle) or not to kinesiotherapy (black squares) and healthy controls (dotted line). Levels of C-X-C motif chemokine 8 (CXCL-8) (A), (C-C motif) ligand 2 (CCL2) (B), CCL-5 (C), CCL-11 (D), and CXCL-10 (E). Error bars represent median \pm standard deviation. (F) Radar plot representation of plasma chemokines. Lines highlight the fold change in cytokine levels in Fogo selvage-patients submitted to kinesiotherapy (dark gray line) in relation to those not submitted to this protocol (light grey line). Data were obtained by calculating the ratio between the median concentrations of each cytokine in the Fogo Selvagem submitted or not to kinesiotherapy (Mann-Whitney test). $\mathrm{PF}$, pemphigus foliaceus.

that this molecule is increased in Pemphigus vulgaris (Timóteo et al., 2017). The results observed in the present study, suggest that kinesiotherapy can be effectively used as adjuvant therapy as well as is able to lower the levels of IL-17 in FS. Despite the scarcity of data regarding the role of IL-17 in the pathogenesis of FS and based on its function in other pathologies of skin, it is feasible to assume that therapies aiming at modulating this cytokine, especially in combination with kinesiotherapy, may present promising results.

Increased levels of different cytokines, including IL-15, characterize chronic inflammation, like that observed in FS. This cytokine is produced by several types of cells like antigen-presenting cells, epidermal skin cells, keratinocytes, and intestinal epithelial cells (Fehniger and Caligiuri, 2001). Furthermore, IL-15 is able to induce the production of other inflammatory cytokines such as IL17 and TNF- $\alpha$, besides of influencing angiogenesis, recruitment of phagocytes and acanthosis (Dunphy and Gardiner, 2011). IL15 has similar biological effects as IL-2, however, distinct key roles were identified during development and function of CD8+ $\mathrm{T}$ cells, natural killer cells, invariant natural killer-T cells, and intestinal intraepithelial lymphocytes (Castillo and Schluns, 2012). High serum levels of IL-15 were implicated in the pathogenesis of pustular palmoplantar psoriasis (Lesiak et al., 2016), which is an infrequent type of psoriasis disturbing primarily distal parts of the limbs. Likewise, higher levels of IL-15 were correlated with the activity of NK cells in the pathogenesis of psoriatic arthritis (Tang et al., 2013). Additionally, IL-15 is also implicated in the pathogenesis of psoriasis through the protection of keratinocytes from apoptosis by the activation of ERK1/2 and PI3 kinase (Waldmann, 2013). Though the role of IL-15 is not clarified in FS, the reduction observed in patients submitted to kinesiotherapy could be beneficial to disease outcome.

Our results indicate how a number of cytokines can behave in front of the practice of physical activity for rehabilitation of an autoimmune disease which can be enlightening for other diseases with the same profile. Therefore, for the first time, we suggest 
that kinesiotherapy can be safely and effectively used as adjuvant therapy to treat FS and reestablish immune balance for having been associated the reduction of pro-inflammatory cytokines related to the disease. More prospective studies are needed to assess the levels of cytokines and their relationship to disease activity and quality of life parameters of patients with FS.

\section{CONFLICT OF INTEREST}

No potential conflict of interest relevant to this article was reported.

\section{ACKNOWLEDGMENTS}

We thank the Fundação de Amparo à Pesquisa do Estado de Minas Gerais (FAPEMIG), Coordenação de Aperfeiçoamento de Pessoal de Nível Superior (CAPES) and Conselho Nacional de Desenvolvimento Científico e Tecnológico (CNPq) for financial support of this study. The funding sources had no involvement in the collection, analysis and interpretation of data; in the writing of the report; and in the decision to submit the article for publication.

\section{SUPPLEMENTARY MATERIAL}

Supplementary Table 1 can be found via https://doi.org/10. 12965/jer.1938146.073.

\section{REFERENCES}

Alexanderson H, Dastmalchi M, Esbjörnsson-Liljedahl M, Opava CH, Lundberg IE. Benefits of intensive resistance training in patients with chronic polymyositis or dermatomyositis. Arthritis Rheum 2007;57: 768-777.

American College of Sports Medicine. American College of Sports Medicine position stand. Progression models in resistance training for healthy adults. Med Sci Sports Exerc 2009;41:687-708.

Aoki V, Rivitti EA, Diaz LA; Cooperative Group on Fogo Selvagem Research. Update on fogo selvagem, an endemic form of pemphigus foliaceus. J Dermatol 2015;42:18-26.

Aqel SI, Hampton JM, Bruss M, Jones KT, Valiente GR, Wu LC, Young MC, Willis WL, Ardoin S, Agarwal S, Bolon B, Powell N, Sheridan J, Schlesinger N, Jarjour WN, Young NA. Daily moderate exercise is beneficial and social stress is detrimental to disease pathology in murine lupus nephritis. Front Physiol 2017;8:236.
Arakawa M, Dainichi T, Yasumoto S, Hashimoto T. Lesional Th17 cells in pemphigus vulgaris and pemphigus foliaceus. J Dermatol Sci 2009;53: 228-231.

Benham H, Norris P, Goodall J, Wechalekar MD, FitzGerald O, Szentpetery A, Smith M, Thomas R, Gaston H. Th17 and Th22 cells in psoriatic arthritis and psoriasis. Arthritis Res Ther 2013;15:R136.

Brenol CV, da Mota LM, Cruz BA, Pileggi GS, Pereira IA, Rezende LS, Bertolo MB, Freitas MV, Silva NA, Louzada-Junior P, Giorgi RD, Lima RA, Pinheiro Gda R; Brazilian Society of Rheumatology. 2012 Brazilian Society of Rheumatology Consensus on vaccination of patients with rheumatoid arthritis. Rev Bras Reumatol 2013;53:4-23.

Castillo EF, Schluns KS. Regulating the immune system via IL-15 transpresentation. Cytokine 2012;59:479-490.

Culton DA, Qian Y, Li N, Rubenstein D, Aoki V, Filhio GH, Rivitti EA, Diaz LA. Advances in pemphigus and its endemic pemphigus foliaceus (Fogo Selvagem) phenotype: a paradigm of human autoimmunity. J Autoimmun 2008;31:311-324.

Dunphy S, Gardiner CM. NK cells and psoriasis. J Biomed Biotechnol 2011; 2011:248317.

Fehniger TA, Caligiuri MA. Interleukin 15: biology and relevance to human disease. Blood 2001;97:14-32.

Grando SA. Pemphigus autoimmunity: hypotheses and realities. Autoimmunity 2012;45:7-35.

Greig SL. Brodalumab: first global approval. Drugs 2016;76:1403-1412.

Hans-Filho G, Aoki V, Bittner NRH, Bittner GC. Fogo selvagem: endemic pemphigus foliaceus. An Bras Dermatol 2018;93:638-650.

Johansen C, Usher PA, Kjellerup RB, Lundsgaard D, Iversen L, Kragballe K. Characterization of the interleukin-17 isoforms and receptors in lesional psoriatic skin. Br J Dermatol 2009;160:319-324.

Kasperkiewicz M, Ellebrecht CT, Takahashi H, Yamagami J, Zillikens D, Payne AS, Amagai M. Pemphigus. Nat Rev Dis Primers 2017;3:17026.

Kimball AB, Gladman D, Gelfand JM, Gordon K, Horn EJ, Korman NJ, Korver G, Krueger GG, Strober BE, Lebwohl MG; National Psoriasis Foundation. National Psoriasis Foundation clinical consensus on psoriasis comorbidities and recommendations for screening. J Am Acad Dermatol 2008;58:1031-1042.

Leicht CA, Goosey-Tolfrey VL, Bishop NC. Spinal cord injury: known and possible influences on the immune response to exercise. Exerc Immunol Rev 2013;19:144-163.

Lesiak A, Bednarski I, Pałczyńska M, Kumiszcza E, Kraska-Gacka M, Woźniacka A, Narbutt J. Are interleukin-15 and -22 a new pathogenic factor in pustular palmoplantar psoriasis? Postepy Dermatol Alergol 2016;33:336-339.

López-Robles E, Avalos-Díaz E, Vega-Memije E, Hojyo-Tomoka T, Villalobos R, Fraire S, Domíguez-Soto L, Herrera-Esparza R. TNF $\alpha$ and 
IL-6 are mediators in the blistering process of pemphigus. Int J Dermatol 2001;40:185-188.

Markham A. Ixekizumab: first global approval. Drugs 2016;76:901-905.

Nograles KE, Zaba LC, Shemer A, Fuentes-Duculan J, Cardinale I, Kikuchi T, Ramon M, Bergman R, Krueger JG, Guttman-Yassky E. IL-22producing "T22" $\mathrm{T}$ cells account for upregulated IL-22 in atopic dermatitis despite reduced IL-17-producing TH17 T cells. J Allergy Clin Immunol 2009;123:1244-1252.e2.

Perandini LA, de Sá-Pinto AL, Roschel H, Benatti FB, Lima FR, Bonfá E, Gualano B. Exercise as a therapeutic tool to counteract inflammation and clinical symptoms in autoimmune rheumatic diseases. Autoimmun Rev 2012;12:218-224.

Rocha-Rodrigues DB, Paschoini G, Pereira SA, dos Reis MA, Teixeira Vde $\mathrm{P}$, Rodrigues Júnior V. High levels of interleukin-1 in patients with endemic pemphigus foliaceus. Clin Diagn Lab Immunol 2003;10:741-743.

Rodrigues DB, Pereira SA, dos Reis MA, Adad SJ, Caixeta JE, Chiba AM, Sousa RA, Rodrigues V Jr. In situ detection of inflammatory cytokines and apoptosis in pemphigus foliaceus patients. Arch Pathol Lab Med 2009;133:97-100.

Rodríguez Huerta MD, Trujillo-Martín MM, Rúa-Figueroa Í, CuellarPompa L, Quirós-López R, Serrano-Aguilar P; Spanish SLE CPG Development Group. Healthy lifestyle habits for patients with systemic lupus erythematosus: a systemic review. Semin Arthritis Rheum 2016; 45:463-470.

Tang F, Sally B, Ciszewski C, Abadie V, Curran SA, Groh V, Fitzgerald O, Winchester RJ, Jabri B. Interleukin 15 primes natural killer cells to kill via NKG2D and CPLA2 and this pathway is active in psoriatic arthritis. PLoS One 2013;8:e76292.

Timóteo RP, Marques LS, Bertoncello D. Physiotherapy intervention promotes better quality of life for individuals with pemphigus. Rev Soc Bras Med Trop 2010;43:580-583.

Timóteo RP, Silva MV, da Silva DAA, Catarino JDS, Alves FHC, Rodrigues Júnior V, Roselino AM, Sales-Campos H, Oliveira CJF. Cytokine and chemokines alterations in the endemic form of pemphigus foliaceus (Fogo Selvagem). Front Immunol 2017;8:978.

Tojo G, Fujimura T, Furudate S, Kambayashi Y, Watabe A, Hashimoto A, Aiba S. Induction of IL-17 producing cells and Foxp3+ regulatory $\mathrm{T}$ cells in areas of skin affected by localized pemphigus folliaceus. Eur J Dermatol 2013;23:711-712.

Trifari S, Kaplan CD, Tran EH, Crellin NK, Spits H. Identification of a human helper $\mathrm{T}$ cell population that has abundant production of interleukin 22 and is distinct from $\mathrm{T}_{\mathrm{H}}-17, \mathrm{~T}_{\mathrm{H}} 1$ and $\mathrm{T}_{\mathrm{H}} 2$ cells. Nat Immunol 2009;10:864-871.

Waldmann TA. The biology of IL-15: implications for cancer therapy and the treatment of autoimmune disorders. J Investig Dermatol Symp Proc 2013;16:S28-30.

Walsh NP, Gleeson M, Pyne DB, Nieman DC, Dhabhar FS, Shephard RJ, Oliver SJ, Bermon S, Kajeniene A. Position statement. Part two: maintaining immune health. Exerc Immunol Rev 2011;17:64-103.

Wolk K, Kunz S, Witte E, Friedrich M, Asadullah K, Sabat R. IL-22 increases the innate immunity of tissues. Immunity 2004;21:241-254. 